\title{
Hybrid One- and Two-sided Flow-Encodings Only (HOTFEO) to accelerate 4D flow MRI
}

\author{
Da Wang ${ }^{1,2^{*}}$, Jiaxin Shao ${ }^{1}$, Daniel B Ennis ${ }^{1,2}$, Peng $\mathrm{Hu}^{1,2}$ \\ From 19th Annual SCMR Scientific Sessions \\ Los Angeles, CA, USA. 27-30 January 2016
}

\section{Background}

4D flow phase-contrast MRI (PC-MRI) has been extensively used for visualization and quantification of blood flow and velocity. It typically acquires one flow-compensated (FC) and three-directional (3D) flow-encoded (FE) echoes (FC/3FE) to update one cardiac phase, which often limits the achievable temporal resolution and temporal footprint for each cardiac phase. In this work, we propose a Hybrid One- and Two-sided Flow-Encodes Only (HOTFEO) acquisition strategy (as shown in Figure 1) that incorporates with a velocity direction constraint (assuming the velocity direction, not magnitude, changes very little between two cardiac phases) to accurately calculate without acquiring FC data to achieve 4/ 3 -fold acceleration. Retrospective and prospective in vivo studies were performed to validate the measurement accuracy of total volumetric flow and maximal total peak velocity.

\section{Methods}

In many vascular territories, such as common carotids arteries (CCAs) and circle of Willis, the blood flow tends to be laminar flow and the velocity direction and the FC signal phase does not change significantly between two cardiac phases $(\sim 140 \mathrm{~ms})$. In our PC-MRI sequence shown in Figure 1, we only acquire the 3D FE data except that the phase-encoding FE acquisition is interleaved two-sided FE. Thus, the velocity direction constraint for cardiac phase $\mathrm{n}$ and $\mathrm{n}+1$ for calculating FC phase $\varphi_{\mathrm{FCn}}\left(=\varphi_{\mathrm{FCn}+1}\right)$ is:

$\varphi_{\mathrm{FCn}}=\left.\operatorname{argmin}_{\varphi \mathrm{FCn}}|| \mathbf{V}_{\mathbf{n}}{ }^{*} \mathbf{V}_{\mathbf{n}+\mathbf{1}}|-| \mathbf{V}_{\mathbf{n}}\right|^{*}\left|\mathbf{V}_{\mathbf{n}+\mathbf{1}}\right| \mid[1]$

$\mathbf{V}_{\mathbf{n}}{ }^{*} \mathbf{V}_{\mathbf{n}+\mathbf{1}}$ is the dot product of two velocity vectors that contains 3D velocity information: $V_{n, x / y / z}=\left(\varphi_{\mathrm{FEn}, \mathrm{x} / \mathrm{y} / \mathrm{z}}\right.$ $\left.\varphi_{\mathrm{FCn}}\right) / \pi^{*} \mathrm{VENC} ; \varphi_{\mathrm{FEn}, \mathrm{x} / \mathrm{y} / \mathrm{z}}$ is the acquired FE phase signal

'Department of Radiological Sciences, David Geffen School of Medicine, University of California, Los Angeles, CA, USA

Full list of author information is available at the end of the article

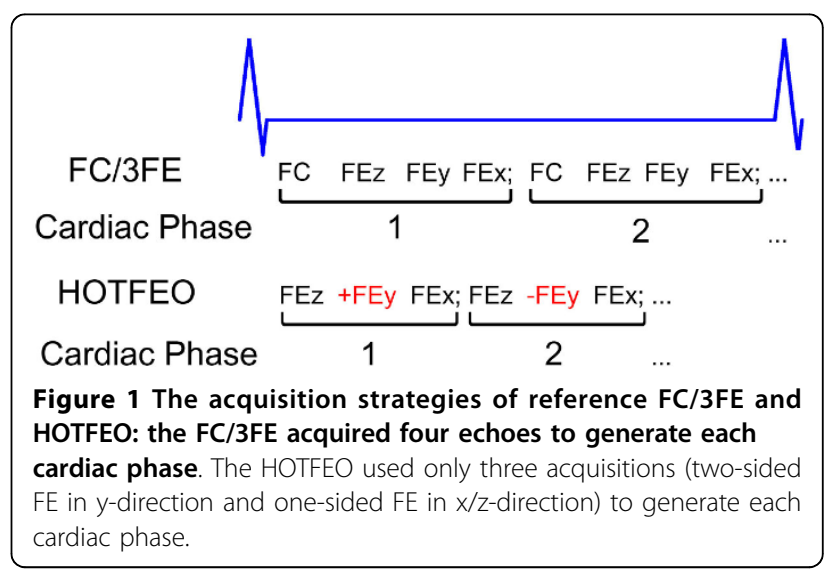

in the $\mathrm{x} / \mathrm{y} / \mathrm{z}$ direction for cardiac phase $\mathrm{n},\left|\mathbf{V}_{\mathbf{n}}\right|$ is the velocity magnitude for cardiac phase n. Eq. [1] essentially minimizes the angle between the velocity directions between two adjacent cardiac phases.

Six healthy volunteers were recruited for retrospective (using standard reference 4D flow data to simulate the HOTFEO acquisition) and prospective in vivo study using a 3T scanner (Skyra, Siemens) with a 4-channel neck coil, using both standard 4D flow and the proposed HOTFEO sequence. Both sequences were implemented with VENC $=100-105 \mathrm{~cm} / \mathrm{s}$, flip angle $=20^{\circ}$, readout bandwidth $=815 \mathrm{~Hz} /$ Pixel, $\mathrm{TE}=3.35 \mathrm{~ms}$, Views-per-segment $=3(\mathrm{FC} / 3 \mathrm{FE})$ and $4(\mathrm{HOTFEO})$, temporal resolution $=68 \mathrm{~ms}$, acquired matrix $=256 \times$ $176 \times 10, \mathrm{FOV}=256 \times 176 \times 18.2 \mathrm{~mm}^{3}$. All scans were acquired during free breathing with prospective ECG gating.

\section{Results}

Compared with standard 4D flow, simulated HOTFEO showed that the FC calculation (Figure 2a) is accurate with mean RMSE $=0.04($ range:0.02-0.06) $\mathrm{rad}$ and 


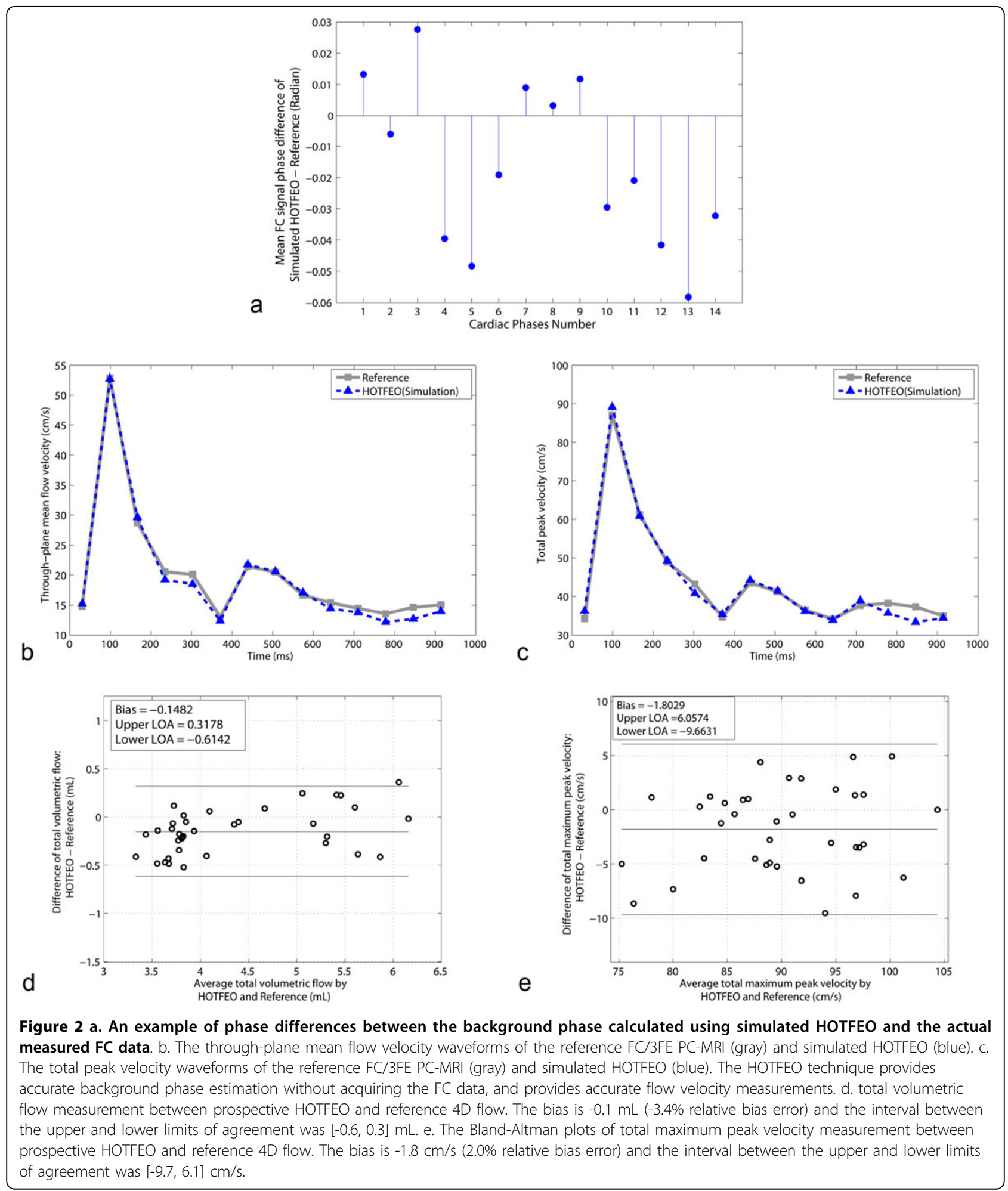

velocity waveforms (Figure $2 \mathrm{bc}$ ) have a good agreement. Bland-Altman tests showed that prospective 4/3-fold accelerated HOTFEO technique resulted in relatively small bias errors and good agreements for total volumetric flow $(-3.4 \%)$, and total maximum peak velocity $(-2.0 \%)$ measurements in CCAs (Figure 2de). 


\section{Conclusions}

HOTFEO can accelerate 4D flow PC-MRI while maintaining the measurement accuracy of total volumetric flow and total maximum peak velocity measurements.

\section{Authors' details}

'Department of Radiological Sciences, David Geffen School of Medicine, University of California, Los Angeles, CA, USA. ${ }^{2}$ Biomedical Physics Interdepartmental Graduate Program, University of California, Los Angeles, CA, USA.

Published: 27 January 2016

doi:10.1186/1532-429X-18-S1-P364

Cite this article as: Wang et al:: Hybrid One- and Two-sided FlowEncodings Only (HOTFEO) to accelerate 4D flow MRI. Journal of

Cardiovascular Magnetic Resonance 2016 18(Suppl 1):P364.

Submit your next manuscript to BioMed Central and take full advantage of:

- Convenient online submission

- Thorough peer review

- No space constraints or color figure charges

- Immediate publication on acceptance

- Inclusion in PubMed, CAS, Scopus and Google Scholar

- Research which is freely available for redistribution

Submit your manuscript at www.biomedcentral.com/submit 